\title{
Death anxiety, self-worth, and exposure to human donor remains: A longitudinal study of Irish medical students
}

Jonathan J. Wolf, Joanne McVeigh, Frédérique Vallières, Philip Hyland \& Malcolm MacLachlan

To cite this article: Jonathan J. Wolf, Joanne McVeigh, Frédérique Vallières, Philip Hyland \& Malcolm MacLachlan (2020): Death anxiety, self-worth, and exposure to human donor remains: A longitudinal study of Irish medical students, Death Studies, DOI: 10.1080/07481187.2020.1783030

To link to this article: https://doi.org/10.1080/07481187.2020.1783030

View supplementary material

曲 Published online: 06 Jul 2020.

Submit your article to this journal $\pi$

Џll Article views: 171

Q View related articles $\sqsubset$

View Crossmark data \lceil 


\title{
Death anxiety, self-worth, and exposure to human donor remains: A longitudinal study of Irish medical students
}

\author{
Jonathan J. Wolfa , Joanne McVeigh ${ }^{\mathrm{b}, c}$, Frédérique Vallières ${ }^{\mathrm{a}, \mathrm{d}} \mathbb{D}$, Philip Hyland ${ }^{\mathrm{c}, \mathrm{d}, \mathrm{e}} \mathbb{D}$, and \\ Malcolm MacLachlan ${ }^{c, d, e, f, g}$

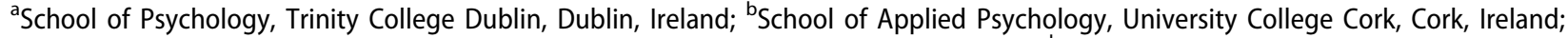 \\ ${ }^{c}$ Assisting Living and Learning (ALL) Institute, Maynooth University, Maynooth, Ireland; ${ }^{d}$ Centre for Global Health, Trinity College

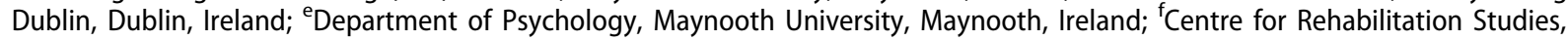 \\ Stellenbosch University, Cape Town, South Africa; ${ }^{9}$ Olomouc University Social Health Institute, Palacký University, Olomouc, \\ Czech Republic
}

\begin{abstract}
This study aimed to investigate the relationship between death anxiety levels at pre-exposure to human donor remains, post-exposure self-worth, and post-exposure death anxiety levels, among a sample of Irish medical students. A multi-wave prospective study was conducted, using questionnaires administered at six time-points. Path analysis was used to investigate the effect of pre-exposure death anxiety levels and post-exposure self-worth on post-exposure death anxiety levels. Baseline death anxiety was found to predict post-exposure death anxiety. Furthermore, self-worth at one month of exposure was found to mediate the relationship between pre-exposure death anxiety levels and death anxiety levels at six months.
\end{abstract}

Trauma research is limited by the ethical implications of purposefully subjecting individuals to traumatic stimuli, by the unpredictability of trauma, and as a consequence, the typical occurrence of trauma in an uncontrolled environment. Much trauma research includes individuals who are likely to be exposed to traumatic stimuli as a result of their profession (for example, military personnel, police officers, and healthcare personnel; Andersen et al., 2019; Ben-Ezra et al., 2011; Firth-Cozens et al., 1999; GeronazzoAlman et al., 2017; Luce et al., 2002). However, while these personnel may be expected to be exposed to traumatic stimuli, the exact type, time, and length of exposure is usually difficult to anticipate.

One such potentially traumatic stimulus is exposure to human remains. While human remains have been used in the study of anatomy for centuries (McLachlan \& Patten, 2006), the practice of human dissection is not without controversy. Exposure to human remains is considered an adverse stimulus and is associated with negative reactions, both psychologically (Arráez-Aybar et al., 2004; Finkelstein \& Mathers, 1990) and physically (Arráez-Aybar et al., 2008; Chang et al., 2018). However, exposure to human remains provides an opportunity to prospectively study the effects of exposure to potentially adverse stimuli, under relatively accessible conditions for researchers. Knowing when first exposure will occur facilitates the measuring of variables preexposure as well as comparable follow-up measures. Furthermore, ethical considerations are less problematic as individuals are voluntarily exposed to human remains. Such a prospective study could also have important implications for individuals who work in professions where human remains have been donated specifically for clinical education purposes (Human Donor Remains [HDR]), contributing to our understanding of how individual characteristics interact with exposure. As part of their training, medical students undergo exposure to HDR, providing an opportunity to undertake a longitudinal study of exposure to adverse stimuli, prior to exposure to HDR up to exposure to patients in a clinical setting.

\section{Death anxiety}

Death anxiety is a psychological construct that can be used to monitor the effects of exposure to HDR and 
exposure to patients in hospital settings. HDR may act as a mortality cue (reminder of death); which may be associated with increased death anxiety, defined by Tomer and Eliason (1996) as "a negative emotional reaction provoked by the anticipation of a state in which the self does not exist" (p. 345). The current study conceptualizes death anxiety as also encompassing fear of death (Lehto \& Stein, 2009). Heightened death anxiety has been shown to have a negative association with mental health, including depression, general anxiety (Conte et al., 1982; Furer \& Walker, 2008; Hintze et al., 1993; Kastenbaum, 2000), and post-traumatic symptoms (Martz, 2004). Moreover, heightened death anxiety has been associated with reduced work capacity (Cochrane et al., 1991; DePaola et al., 1994; Neimeyer, 2009; Neimeyer et al., 2004; Ulla et al., 2003), burnout (Melo \& Oliver, 2011), and negative attitudes toward dying patients (Peters et al., 2013). Lehto and Stein (2009) argue that death anxiety could be both a source of negative affect and of therapeutic intervention. As healthcare workers may be exposed to reminders of death (mortality cues) on a daily basis, it becomes apparent that understanding and managing death anxiety may be important not only for healthcare personnel themselves but also for their patients.

An important theoretical framework within death anxiety research is Terror Management Theory (TMT; Greenberg et al., 1986). TMT proposes that people's intellectual capacity to understand that death is an unavoidable result of life itself (Greenberg et al., 1986) can create a state of anxiety, which can be protected against by cultural world views that provide meaning and an opportunity to gain self-esteem within this meaning (Pyszczynski et al., 1999; Rosenblatt et al., 1989). Whereas cultural world views refer to shared cultural conceptions that mitigate anxiety about the inevitability of death by affirming one's symbolic immortality ("death transcending identity") or literal immortality (the belief in an eternal soul), self-esteem refers to the belief that one is a valuable contributor to one's world (Greenberg \& Arndt, 2012).

TMT researchers have utilized two hypotheses in their investigations (Pyszczynski et al., 1999). First, the anxiety buffer hypothesis stipulates that selfesteem protects against anxiety; increased self-esteem should result in one being "less prone to anxiety and anxiety- related behavior" (Pyszczynski et al., 1999, p. 836). Second, the mortality salience hypothesis stipulates that due to cultural worldviews and self-esteem being protective psychological constructs against anxiety, exposure to mortality cues would increase the individual's need for these structures (Harmon-Jones et al., 1997). Thus, individuals who are exposed to mortality cues will behave in ways that support their cultural worldviews and self-esteem. Much multimethodological research has supported the anxiety buffer hypothesis, chosen as the theoretical basis for the current study (e.g., Cicirelli, 2002; Du et al., 2013; Greenberg et al., 1992; Pyszczynski et al., 2004; Routledge, 2012; Routledge et al., 2010).

\section{Human donor remains and death anxiety}

Anatomy, originating from the Greek work "anatome" signifying "cutting up", explores the structure of the body, and is a fundamental science subject taken by medical students at the initiation of their medical education (Ghazanfar et al., 2018). The gross anatomy laboratory is a critical rite of passage in the creation of medical students' learning and identity as professionals (Chiou et al., 2017). As suggested by Madill and Latchford (2005, p. 1638), "perhaps the most universal and recognizable step in making the transition from lay-person to doctor-in-training is the process of conducting human dissection in the gross anatomy laboratory." The gross anatomy laboratory may implicitly threaten to filter students in terms of those who can or cannot cope with exposure to human donor remains. Several stressors during this time may result in students experiencing general anxiety in relation to the beginning of their medical education and their subsequent medical practice.

Dissection of human donor remains may be a critical component of medical education. For example, donor dissection may prime students' focus on ethics in medical practice, as an anatomical education poses ethical considerations such as consent, dignity, beneficence, and the dichotomy of objectification and personification (Stephens et al., 2019). Pre-clinical training may impact on the prevalence of burn-out among medical students, as students must develop professional competencies and coping mechanisms such as "detached concern" during this training period (Boeckers \& Boeckers, 2016). However, coping mechanisms adopted by medical students, such as detachment and indifference to the dissection of the cadaver, may lead to entrenched negative attitudes when students ultimately graduate as doctors (Saw, 2018). Accordingly, detachment may be required for students to carry out donor dissections and to practice medicine effectively upon graduation, but there is a risk that such detachment may have adverse consequences for care (Stephens et al., 2019). Indeed, 
several medical schools globally carry out memorial ceremonies of gratitude toward cadaver donors for the purpose of instilling humanistic values in students, including respect, altruism, and responsibility (Chang et al., 2018).

Few studies have investigated the specific relationship between exposure to HDR and death anxiety levels (DAL) in medical students. One study, carried out by Dickinson et al. (1997), monitored DAL of 84 firstyear medical students in two time periods: before exposure to HDR and at the end of a one-semester gross anatomy course. Dickinson et al. found that over a quarter $(28.6 \%)$ of participants suffered from an increase in death anxiety. This same study, however, did not consider other possible variables that may contribute to this observed reaction among students. A later study undertaken by Arráez-Aybar et al. (2008) did however note risk and resilience factors in exposure to HDR. Monitoring DAL of 425 pre-HDRexposure anatomy students, Arráez-Aybar and colleagues reported that students who tended to conceptualize HDR as former living human beings, also suffered from significantly higher DAL. Conversely, students who reported that they felt well-prepared to work with HDR had significantly lower DAL than their peers who felt relatively poorly prepared. Furthermore, Arráez-Aybar et al. also found that increased DAL pre-dissection was associated with increased thinking about death during dissection. These studies by Dickinson et al. (1997) and ArráezAybar et al. (2008) provide valuable information about DAL before and after exposure to HDR, and about both protective factors and risk factors of HDR-associated DAL. However, they do not concurrently assess other psychological constructs related to DAL, which may have important mediating or moderating roles in the relationship between exposure to HDR, psychological affect, and performance, or more generally between trauma and well-being.

To date, one peer-reviewed study has been reported concerning exposure to HDR and TMT. Hughes and Black (2006) investigated the relationship between body-esteem, exposure to HDR, and physiological stress, as measured by blood pressure and heart rate. The researchers sampled second year anatomy students over four sampling periods: when the practical began, and after 30,60 and $90 \mathrm{~min}$ of the practical. They found that participants who were rated as having low body-esteem also had lower pulse pressure at all sampling times than their high body-esteem colleagues. Hughes and Black concluded that high bodyesteem was a risk factor when exposed to HDR. They further noted that this was consistent with TMT in that students who use their high body-esteem as a source to buffer anxiety are more likely to suffer from increased stress when exposed to a stimulus (i.e. HDR) that reminds them of the vulnerability of that source of esteem.

\section{Research aim}

Notwithstanding the aforementioned studies, there is a dearth of prospective longitudinal studies in the literature on DAL. The effect of baseline death anxiety has also been neglected in the literature. Anchoring the current study in a theoretical perspective overcomes a further limitation of death anxiety research. As noted by Neimeyer et al. (2004), the literature in this research area tends to be atheoretical and lacks advanced statistical analyses. Similar to HDR research, death anxiety research has therefore been largely atheoretical (Kastenbaum, 2000). Indeed, in commenting on the atheoretical nature of death attitudes research (including death anxiety), Neimeyer et al. (2004) stated:

In general, research on death attitudes has tended to follow an atheoretical statistical dragnet method, as investigators simply report significant associations between variables, or at most test interesting but isolated hypotheses that have little or no relation to broader theories of human functioning. (p. 327)

According to Neimeyer and colleagues, a more theoretically grounded approach would enable broader application of research findings; yet such research should also embrace more sophisticated statistical techniques, allowing for stronger hypothesis testing of theoretically grounded work.

To date, no study has investigated the relationship between exposure to HDR and death anxiety within a TMT framework. The current study addresses this research gap by undertaking a prospective longitudinal study of medical students exposed to HDR within a TMT framework. Medical students were assessed prior to exposure to HDR, up to exposure to patients in a clinical setting during their third year of study. The primary aim of this study was to investigate the relationship between death anxiety levels at pre-exposure to HDR, post-exposure self-worth, and post-exposure death anxiety levels, among a sample of Irish medical students.

We hypothesized that self-worth would mediate the relationship between pre- and post-mortality cue exposure DAL. In accordance with TMT, research has shown that increasing self-esteem has a positive effect 
on reducing death anxiety (e.g., Routledge, 2012), and that an individual's need for self-esteem increases when exposed to mortality cues (e.g., Pyszczynski et al., 2004). As suggested by Greenberg (2008), "If self-esteem protects people from mortality concerns, then reminders of mortality should intensify striving for self-esteem" (p. 50). Pyszczynski and Kesebir (2011) noted that "terror management theory suggests that a sense of self-worth is an essential component of the existential anxiety-buffering system" (p. 9). Correspondingly, the World Assumptions Theory (Janoff-Bulman, 1989, 1992) posits that a traumatic event could lead an individual to face a reality that is incongruent with their basic assumptions (Elklit et al., 2007), which in turn, could lead to psychological distress (Grills-Taquechel et al., 2011). One of the world assumptions proposed by Janoff-Bulman $(1989,1992)$ is self-worth. Accordingly, self-worth may mediate pre- and post-exposure DAL. Indeed, self-esteem modulations may mediate the effects of mortality salience (Echebarria Echabe \& Perez, 2016). As proposed by Klackl and Jonas (2019), TMT usually theorizes self-esteem modulations as a buffer against existential anxiety, although it may also mediate the effects of mortality salience.

\section{Methods}

\section{Participants and procedures}

First year medical students volunteered to take part in the study. The students were from two Irish medical schools: Trinity College Dublin (TCD) and University College Dublin (UCD). A total sample of 436 students participated in the study (209 male and 228 female); and ages of the students ranged from 17 to 43 $(M=20.08, S D=2.72)$. The TCD student group was composed of 194 students (97 male and 97 Female), with an age range of 17 to $43(M=20.29, S D=3.20)$. The UCD student group comprised 242 students (111 male and 131 female), with an age range of 18 to 34 $(M=19.93, S D=1.87)$.

A multi-wave prospective study was conducted, using questionnaires administered at six time points. Students were sampled before exposure (baseline), immediately after first exposure (wave 1), after one month of exposure (wave 2), after six months of exposure (wave 3), after 18 months of exposure (wave 4 ), and finally after 30 months of exposure (wave 5). Of note, UCD students were not sampled from wave 4 onwards, as the UCD School of Medicine decided not to participate. The study took place between September 2010 and March 2013.
Table 1. Response rates across time points.

\begin{tabular}{lcccc}
\hline Sampling Period & $n$ & Response rate & Male & Female \\
\hline Baseline & 312 & $71.39 \%$ & 143 & 169 \\
Wave 1 & 312 & $71.39 \%$ & 145 & 167 \\
Wave 2 & 286 & $65.44 \%$ & 126 & 160 \\
Wave 3 & 259 & $59.26 \%$ & 115 & 144 \\
Wave 4 & 77 & $39.69 \%$ & 29 & 48 \\
Wave 5 & 111 & $57.21 \%$ & 43 & 68 \\
\hline
\end{tabular}

Note. Response rates up to wave 3 are calculated as a subset of the total sample, including both TCD and UCD students $(N=436)$. Response rates for waves 4 and 5 are calculated as a subset of the total number of TCD students, as only TCD students participated in waves 4 and $5(n=194)$.

At each sampling period, a convenience sample was taken based on the number of students in class at each time; doing so removed potential sampling error through random identification of a predetermined number based on effect size calculations. Response rates across time points are provided in Table 1.

Baseline questionnaires were completed during orientation, which took place at the start of the academic year. Students entering the anatomy lecture hall were greeted by academic staff, who subsequently explained the syllabus for the upcoming academic year, including any upcoming work with HDR. Students were then informed about the study and gave their written consent to take part in the study. Thereafter, they were asked to complete the first questionnaire. Wave 1 was undertaken immediately after first exposure to HDR. Waves 2-4 were conducted following anatomy lectures. Finally, wave 5 data collection took place in TCD following a pathology lecture in the hospital, where participants encountered their first clinical exposure to HDR. Ethical approval was granted by [redacted for anonymity purposes]. Students completed the questionnaires voluntarily and anonymously, using a unique participant identification number.

\section{Materials}

\section{Death anxiety}

Developed by Conte et al. (1982), the Death Anxiety Questionnaire (DAQ) includes a total of 15 items capturing how much an individual worries about different aspects of death. Answers to each item range from 0 ("not at all"), to 1 ("somewhat"), and 2 ("very much"). Sample items of the DAQ include: "Do you worry about dying?" and "Are you worried about not knowing what to expect after death?" A death anxiety score is calculated based on the sum of all 15-item rankings. The DAQ was administered five times throughout the 30-month follow up (at baseline, and at waves $1,3,4$, and 5). The internal reliability was: 
$\mathrm{DAL}_{\text {baseline }} \alpha=0.84, \mathrm{DAL}_{1} \alpha=0.88, \mathrm{DAL}_{3} \alpha=0.90$, $\mathrm{DAL}_{4} \quad \alpha=0.85$, and $\mathrm{DAL}_{5} \quad \alpha=0.84$. Total DAL descriptive statistics for each sampling period are available in Table 2.

\section{World assumptions}

Developed by Janoff-Bulman (1998), the World Assumptions Scale (WAS) includes 32 items, which measure an individual's attitudes and beliefs following traumatic events (Elklit et al., 2007). The WAS includes eight factors: benevolence of the world, benevolence of people, justice, controllability, chance, selfworth, self-controllability, and luck (Dekel et al., 2004). Participants are asked to indicate how much they agree with the statements provided in each item, with answers ranging from 1 ("strongly disagree") to 6 ("strongly agree"). Negatively worded items are reversed before scores on each of the 8 scales are summed.

The WAS is the most widely used measure of cognitions after traumatic events (Elklit et al., 2007). It was chosen for the current study as its assumptions

Table 2. Descriptive statistics for total DAL and SW at different sampling periods.

\begin{tabular}{lrccccc}
\hline Sampling period & $N$ & Missing & $M$ & $S D$ & $\mathrm{LL}$ & $\mathrm{UL}$ \\
\hline DAL $_{\text {baseline }}$ & 302 & 135 & 7.81 & 4.69 & 0 & 22 \\
DAL $_{1}$ & 304 & 133 & 8.21 & 4.81 & 0 & 22 \\
DAL $_{3}$ & 257 & 180 & 7.61 & 4.96 & 0 & 22 \\
DAL $_{4}$ & 76 & 361 & 6.55 & 8.74 & 0 & 15 \\
DAL $_{5}$ & 109 & 328 & 8.20 & 7.42 & 0 & 19 \\
SW $_{\text {baseline }}$ & 298 & 138 & 13.75 & 1.88 & 5.00 & 18.00 \\
WW $_{2}$ & 284 & 153 & 13.52 & 2.10 & 4.00 & 18.00 \\
SW $_{5}$ & 110 & 327 & 14.01 & 5.24 & 3.00 & 18.00 \\
\hline
\end{tabular}

Note. $M=$ Mean; $S D=$ Standard Deviation; $L L=$ Lower Limit; $U L=$ Upper Limit. "closely correspond to what terror management theory refers to as cultural worldviews" (Pyszczynski \& Kesebir, 2011, p. 8). In particular, self-worth was used because, as Pyszczynski and Kesebir note, "terror management theory suggests that a sense of self-worth is an essential component of the existential anxietybuffering system" (p. 9). Thus, the WAS provides the opportunity to measure changes in TMT-related cognitions (self-worth) after exposure to adverse stimuli. The self-worth (SW) internal reliability values were as follows: $\mathrm{SW}_{\text {baseline }} \alpha=0.71, \mathrm{SW}_{2} \alpha=0.73$, and $\mathrm{SW}_{5} \alpha=0.84$.

\section{Data analysis}

The hypothesis (see Figure 1) was tested using the Hayes PROCESS macro (version 2.13) for SPSS (2014). Here, the interest was therefore in the specific indirect effects of the variables hypothesized to mediate the relationship between our independent $\left(\mathrm{DAL}_{\text {baseline }}\right)$ and dependent variable $\left(\mathrm{DAL}_{\text {endline; }}\right.$; Preacher \& Kelley, 2011). The PROCESS macro was chosen because it uses bootstrapping methods for estimating both total and specific indirect effects, as well as to contrast different indirect effects. Bootstrapping is recommended over other causal steps approaches (i.e. the Sobel Test) on the grounds that it retains higher statistical power, while simultaneously retaining reasonable control over the Type I error rate (Cheung \& Lau, 2008).

\section{Results}

Descriptive statistics for total DAL and self-worth are provided in Table 2.

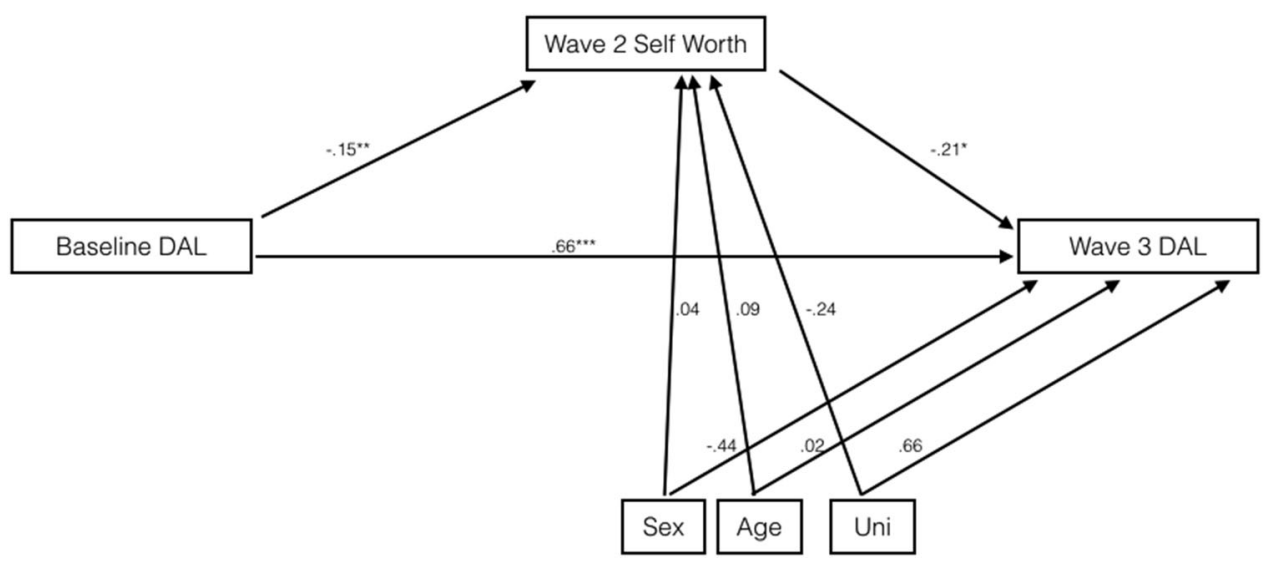

Figure 1. The relationship between $\mathrm{DAL}_{\text {baseline }}$ and $\mathrm{DAL}_{3}$ as mediated by $\mathrm{SW}_{2}$. Note. $N=172$; Baseline DAL = Baseline Death Anxiety Levels; Uni=University Affiliation; Wave 3 DAL =Wave 3 Death Anxiety Levels; ${ }^{*} p<.05 ; * * p<.01 ; * * * p<.001$. 
Table 3. Total model effect and direct effect of $D A L_{\text {baseline }}$ on $\mathrm{DAL}_{3}$ with $\mathrm{SW}_{2}$ as the mediating variable.

\begin{tabular}{lccccccc}
\hline & & & & & \multicolumn{2}{c}{$95 \% \mathrm{Cl}$} \\
\cline { 5 - 7 } & Effect & SE & $t$ & $p$ & Lower & Upper \\
\hline DAL & 0.66 & 0.06 & 10.26 & .00 & 0.53 & 0.79 \\
Total effect & 0.69 & 0.06 & 10.90 & .000 & 0.57 & 0.81 \\
\hline
\end{tabular}

Note. $\mathrm{N}=172 ; \mathrm{Cl}=$ Confidence Interval; $\mathrm{SE}=$ Standard Error.

\section{Analyses of attrition}

Due to the attrition throughout the study, independent samples t-tests on all main variables were conducted to investigate if participants who participated in all waves differed from those who did not. No significant differences were found in death anxiety levels of responders $(M=7.81, S D=4.43)$ and non-responders $(M=7.81, \quad S D=4.84) ; \quad t(300)=$ $-.004, p=.99$. Furthermore, no significant differences were found in wave 2 self-worth scores between responders $(M=13.27, S D=3.01)$ and non-responders $(M=13.88, \quad S D=2.80) ; \quad t(282)=1.75, \quad p=0.08$. Finally, no significant differences were found in wave 3 death anxiety levels between responders $(M=7.83, S D=4.82)$ and non-responders $(M=7.26$, $S D=5.07) ; t(254)=-.885, p=.37$.

\section{Path analyses}

The first path analysis tested the relationship between $\mathrm{DAL}_{\text {baseline }}$ and $\mathrm{DAL}_{3}$, as mediated by $\mathrm{WAS}_{2}$ (Figure 1). Note that CFA was conducted for the WAS, and 7 factors were found (Appendix - see supplementary materials); only self-worth mediated the relationship between baseline and post-exposure DAL. $\mathrm{SW}_{2}$ was found to mediate the relationship between $\mathrm{DAL}_{\text {baseline }}$ and $\mathrm{DAL}_{3}$. Specifically, results suggest that baseline DAL had a significant, direct effect on $\mathrm{DAL}_{3}(B=.66, p<.001)$, and that $\mathrm{SW}_{2}$ partially mediated this relationship (Tables 3 and 4 ). Indeed, the effect of $\mathrm{DAL}_{\text {baseline }}$ on $\mathrm{SW}_{2}$ was significant $(B=-.15, p<.01)$, and intern $\mathrm{SW}_{2}$ had a negative, significant effect on $\mathrm{DAL}_{3}(B=-.21, p<.01)$.

In order to investigate if this model could still hold at later sampling periods and when exposed to different adverse stimuli (patients in a clinical setting at wave 5 as opposed to HDR in waves three and four), two further path analyses were conducted. The first analysis investigated the relationship between baseline and $\mathrm{DAL}_{4}$ as mediated by $\mathrm{SW}_{2}$. The second analysis investigated the relationship between baseline and $\mathrm{DAL}_{5}$ as mediated by $\mathrm{SW}_{2}$. In both analyses, the covariates were sex and age. University affiliation was no
Table 4. Indirect effect of $\mathrm{SW}_{2}$ as mediator of the relationship between $\mathrm{DAL}_{\text {baseline }}$ and $\mathrm{DAL}_{3}$.

\begin{tabular}{lcccc}
\hline & & & \multicolumn{2}{c}{$95 \% \mathrm{Cl}$} \\
\cline { 3 - 5 } & Effect & $\mathrm{SE}$ & Lower & Upper \\
\hline SW & 0.03 & 0.02 & 0.004 & 0.08 \\
\hline Note. $N=172 ; \mathrm{Cl}=$ Confidence Interval; $\mathrm{SE}=$ Standard Error.
\end{tabular}

longer entered as a covariate as only students from TCD participated in the study from wave 4 onwards. $\mathrm{SW}_{2}$ did not significantly mediate the relationship

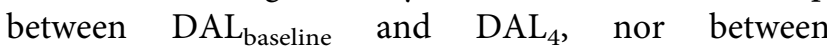
$\mathrm{DAL}_{\text {baseline }}$ and $\mathrm{DAL}_{5}$. However, $\mathrm{SW}_{2}$ was found to have a significant effect on $\mathrm{DAL}_{4}(B=-.28, p<.05)$.

\section{Discussion}

The primary aim of this study was to investigate the relationship between death anxiety levels at pre-exposure to HDR, post-exposure self-worth, and postexposure death anxiety levels, among a sample of Irish medical students. The first path analysis found that $\mathrm{SW}_{2}$ mediated the relationship between $\mathrm{DAL}_{\text {baseline }}$ (pre-exposure) and $\mathrm{DAL}_{3}$. While increased $\mathrm{DAL}_{\text {baseline }}$ predicted increased $\mathrm{DAL}_{3}$, increased $\mathrm{DAL}_{\text {baseline }}$ predicted reduced $\mathrm{SW}_{2}$, and in turn increased $\mathrm{SW}_{2}$ predicted decreased $\mathrm{DAL}_{3}$. Further path analyses found that $\mathrm{SW}_{2}$ predicted decreased $\mathrm{DAL}_{4}$, but did not mediate the relationship between $\mathrm{DAL}_{\text {baseline }}$ and $\mathrm{DAL}_{4}$, and that $\mathrm{SW}_{2}$ did not mediate the relationship between $\mathrm{DAL}_{\text {baseline }}$ and $\mathrm{DAL}_{5}$ nor predict $\mathrm{DAL}_{5}$.

The findings that increased self-worth predicted decreased $\mathrm{DAL}_{3}$ and $\mathrm{DAL}_{4}$ is consistent with the TMT buffer zone hypothesis (Pyszczynski et al., 1999). Indeed, the current study provides further support for multi-methodological and cross-cultural research reporting that self-worth protects against anxiety (Cai et al., 2009; Cicirelli, 2002; Du et al., 2013; Pyszczynski et al., 2004; Routledge, 2012; van Tuijl et al., 2016).

With reference to $\mathrm{SW}_{2}$ no longer predicting total DAL at wave 5 (when students were in a clinical setting), the interval from the measure of $\mathrm{SW}_{2}$ may have been too long to have had an effect on $\mathrm{DAL}_{5}$. Future research should attempt to undertake a measure of self-worth that is temporally closer to exposure to patients in a clinical setting. Indeed, the current study did conduct a measure of self-worth at wave 5 . However, this measure was undertaken at the same time as the total DAL measure; and in order for a mediation analysis to be undertaken, the potential mediator has to occur between the baseline and outcome measures. 
Importantly, the path analyses enabled monitoring of the effects of baseline death anxiety - an effect that was neglected in the literature. Throughout the study, the single most salient predictor of later death anxiety was baseline death anxiety. $\mathrm{DAL}_{\text {baseline was found to }}$ be a significant predictor of $\mathrm{DAL}_{3}, \mathrm{DAL}_{4}$, and $\mathrm{DAL}_{5}$. While the effects of $\mathrm{DAL}_{\text {baseline }}$ on $\mathrm{DAL}_{3}$ were mediated by $\mathrm{SW}_{2}$, no such mediation effects were found in the path models including $\mathrm{DAL}_{4}$ and $\mathrm{DAL}_{5}$. Notably, at wave 3, students were in their first year of anatomy and were exposed to the body (neck downwards) and not the face; at wave 4 , students were in their second year of anatomy and were exposed to the face but not the body; and at wave 5, they were exposed to patients in a clinical setting. This suggests that while preexposure DAL had a similar longitudinal effect on post-exposure DAL, pre-exposure DAL had a differential effect on post-exposure self-worth, which was dependent on the type of mortality cue to which the students were exposed.

This differential effect may be explained by exposure to HDR faces, which may have an extremely salient effect on exposed individuals (e.g., Arráez-Aybar et al., 2008; Finkelstein \& Mathers, 1990; Snelling et al., 2003). The measurement of $\mathrm{SW}_{2}$ occurred before exposure to faces in anatomy class. Therefore, wave 4 exposure to faces may have had such a salient effect on DAL that it rendered the effects of $\mathrm{DAL}_{\text {baseline }}$ on $\mathrm{SW}_{2}$ obsolete. The direct effect of $\mathrm{DAL}_{\text {baseline }}$ and $\mathrm{SW}_{2}$ on $\mathrm{DAL}_{4}$ may have had such an effect on the overall model that it rendered the effect of $\mathrm{DAL}_{\text {baseline }}$ on $\mathrm{SW}_{2}$ non-significant. Nonetheless, in accordance with the TMT buffer zone hypothesis (Pyszczynski et al., 1999), increased $\mathrm{SW}_{2}$ predicted decreased $\mathrm{DAL}_{4}$.

However, in the path model predicting $\mathrm{DAL}_{5}$, not

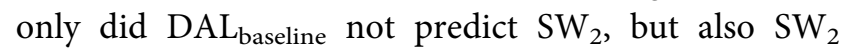
did not predict $\mathrm{DAL}_{5}$. Yet again, exposure to patients in a clinical setting at wave 5 may have rendered the effect of $\mathrm{DAL}_{\text {baseline }}$ on $\mathrm{SW}_{2}$ obsolete. Indeed, general anxiety has a significant effect on death anxiety (e.g., Conte et al. 1982; Furer \& Walker, 2008; Hintze et al., 1993); therefore, working in a new environment (a hospital) may have elevated general anxiety levels and thus increased DAL. This strong correlation between DAL and general anxiety could have rendered the effect of $\mathrm{DAL}_{\text {baseline }}$ on $\mathrm{SW}_{2}$ as non-significant in the model. With reference to the non-significant effect of $\mathrm{SW}_{2}$ on $\mathrm{DAL}_{5}$, as noted above, the interval may have been too long from the self-worth measurement to have observed an effect on $\mathrm{DAL}_{5}$.
The above results suggest that a comprehensive model of death anxiety should include pre-mortalitycue exposure DAL. Indeed, this supplements TMT by stressing that it is not only post-exposure psychological constructs such as self-worth that affect death anxiety but also pre-exposure DAL. From an applied perspective, a model that includes both pre-exposure DAL and post-exposure self-worth has important clinical significance; an intervention aimed at increasing resilience amidst exposure to mortality cues should focus on reducing pre-exposure death anxiety, while an intervention aimed at reducing post-exposure death anxiety should focus on increasing post-exposure self-worth. As evident by the findings, even when the type of exposure in pre-known, knowing which variables to address at different times can affect the outcome.

The assertion of increasing post-exposure self-worth levels is directly in line with TMT, which not only stipulates that increased self-worth reduces death anxiety (Pyszczynski et al., 1999), but also that exposure to anxiety-provoking mortality cues will increase the need for self-worth (Greenberg, 2008). Furthermore, reducing DAL prior to exposure is consistent with the work of Lehto and Stein (2009), who noted that DAL could be a source of therapeutic intervention.

Correspondingly, Bödvarsdóttir and Elklit (2004) found a significant relationship between self-worth and post-traumatic stress disorder symptoms - symptoms that were found to correlate with death anxiety (Martz, 2004). However, a limiting factor of their study was its retrospective nature; sampling was undertaken only 3 months following a traumatic event (an earthquake). Therefore, the researchers could not conclusively determine whether pre-exposure low selfworth was associated with negative reactions to trauma, or whether trauma resulted in reduced selfworth. The current findings suggest that self-worth affects subsequent psychological adversity, but psychological adversity also affects self-worth.

\section{Limitations and future research}

The discontinuation of UCD students from wave 4 resulted in a reduced number of participants, decreasing the power of the study. However, despite the loss of participants at wave 4 , in accordance with the TMT buffer zone hypothesis, $\mathrm{SW}_{2}$ was still found to predict $\mathrm{DAL}_{4}$. A further limitation was the lack of a general anxiety measure at baseline. $\mathrm{DAL}_{\text {baseline may have }}$ been contaminated with general anxiety due to the participants being new to the academic environment. Indeed, as noted above, the literature indicates that 
general anxiety significantly correlates with death anxiety (Conte et al., 1982; Furer \& Walker, 2008; Hintze et al., 1993). The absence of a general anxiety measure made it impossible to determine the extent to which anxiety was due to state, trait, or death anxiety.

Notwithstanding the above limitations, this study utilized advanced statistical analyses to contribute to the literature on the role of self-worth as a mediator between baseline and post-exposure DAL, and its findings have important theoretical and applied importance. From a theoretical perspective, the findings provide support for the TMT buffer zone hypothesis (Pyszczynski et al., 1999), and provide initial information about the effect of pre-mortality cue exposure DAL on subsequent DAL. From an applied perspective, the findings suggest a dual therapeutic approach: reducing pre-exposure DAL and increasing post-exposure self-worth in order to curb postexposure DAL. These potential therapeutic approaches cannot be underestimated in light of the multiple psychological difficulties associated with elevated DAL, and the negative effect that increased DAL can have on work capacity of healthcare personnel (Cochrane et al., 1991; DePaola et al., 1994; Neimeyer, 2009; Neimeyer et al., 2004; Ulla et al., 2003).

The above results suggest that a comprehensive model of death anxiety should include pre-mortalitycue-exposure DAL. Future research should also incorporate both general anxiety measures and personality inventories. Furthermore, it should investigate the relationship between death anxiety at different sampling periods; for example, does death anxiety at wave four (last pre-clinical year) predict death anxiety at wave five (first clinical year)? A more complex question might ask if there is a significant difference in the predictive power of later death anxiety at certain sampling periods than other sampling periods.

It is important to note that alternative approaches for gross anatomy lectures have been developed, including prosection by qualified anatomists during demonstrations for students (Saw, 2018), non-cadaveric models (Mulu \& Tegabu, 2012), 3D prints, and virtual simulations (Habicht et al., 2018). An important area of future research, therefore, is the relationship between exposure to HDR and death anxiety, in relation to alternative approaches for gross anatomy. While the focus of this study was on death anxiety and self-worth, future research could also explore additional psychological factors at baseline and follow-up, such as levels of depression. Other factors that may be of interest include the effects of different levels of religiosity/spirituality amongst samples of medical students.

\section{Data availability statement}

The data that support the findings of this study are available from the corresponding author (JW), upon reasonable request.

\section{ORCID}

Frédérique Vallières (iD) http://orcid.org/0000-00016315-3029

Philip Hyland (D) http://orcid.org/0000-0002-9574-7128

Malcolm MacLachlan (D) http://orcid.org/0000-00016672-9206

\section{References}

Andersen, L. P., Hogh, A., Elklit, A., Hviid Andersen, J., \& Biering, K. (2019). Work-related threats and violence and post-traumatic symptoms in four high-risk occupations: Short- and long-term symptoms. International Archives of Occupational and Environmental Health, 92(2), 195-208. https://doi.org/10.1007/s00420-018-1369-5

Arráez-Aybar, L.-A., Casado-Morales, M.-I., \& CastañoCollado, G. (2004). Anxiety and dissection of the human cadaver: An unsolvable relationship? The Anatomical Record Part B: The New Anatomist, 279B(1), 16-23. https://doi.org/10.1002/ar.b20022

Arráez-Aybar, L.-A., Castaño-Collado, G., \& CasadoMorales, M.-I. (2008). Dissection as a modulator of emotional attitudes and reactions of future health professionals. Medical Education, 42(6), 563-571. https://doi. org/10.1111/j.1365-2923.2008.03079.x

Ben-Ezra, M., Palgi, Y., Wolf, J. J., \& Shrira, A. (2011). Psychiatric symptoms and psychosocial functioning among hospital personnel during the Gaza War: A repeated cross-sectional study. Psychiatry Research, 189(3), 392-395. https://doi.org/10.1016/j.psychres.2011. 02.004

Bödvarsdóttir, I., \& Elklit, A. (2004). Psychological reactions in Icelandic earthquake survivors. Scandinavian Journal of Psychology, 45(1), 3-13. https://doi.org/10.1111/j.14679450.2004.00373.x

Boeckers, A., \& Boeckers, T. M. (2016). The dissection course - A psychological burden or an opportunity to teach core medical competencies: A narrative review of the literature. European Journal of Anatomy, 20(4), 287-298.

Cai, H., Wu, Q., \& Brown, J. D. (2009). Is self-esteem a universal need? Evidence from the People's Republic of China. Asian Journal of Social Psychology, 12(2), 104-120. https://doi.org/10.1111/j.1467-839X.2009.01278.x

Chang, H.-J., Jung Kim, H., Joo Rhyu, I., Lee, Y.-M., \& Uhm, C.-S. (2018). Emotional experiences of medical students during cadaver dissection and the role of memorial ceremonies: A qualitative study. BMC Medical Education, 18(1), 1-7. https://doi.org/10.1186/s12909-018-1358-0 
Cheung, G. W., \& Lau, R. S. (2008). Testing mediation and suppression effects of latent variables: Bootstrapping with structural equation models. Organizational Research Methods, 11(2), 296-325. https://doi.org/10.1177/ 1094428107300343

Chiou, R.-J., Tsai, P.-F., \& Han, D.-Y. (2017). Effects of a "silent mentor" initiation ceremony and dissection on medical students' humanity and learning. BMC Research Notes, 10, 483. https://doi.org/10.1186/s13104-017-2809-0

Cicirelli, V. G. (2002). Fear of death in older adults: Predictions from terror management theory. The Journals of Gerontology Series B: Psychological Sciences and Social Sciences, 57(4), P358-366. https://doi.org/10.1093/geronb/ 57.4.P358

Cochrane, J. B., Levy, M. R., Fryer, J. E., \& Oglesby, C. A. (1991). Death anxiety, disclosure behaviors, and attitudes of oncologists toward terminal care. OMEGA - Journal of Death and Dying, 22(1), 1-12. https://doi.org/10.2190/ LTB4-DARH-AH13-TGN1

Conte, H. R., Weiner, M. B., \& Plutchik, R. (1982). Measuring death anxiety: Conceptual, psychometric, and factor-analytic aspects. Journal of Personality and Social Psychology, 43(4), 775-785. https://doi.org/10.1037/00223514.43.4.775

Dekel, R., Solomon, Z., Elklit, A., \& Ginzburg, K. (2004). World assumptions and combat-related posttraumatic stress disorder. The Journal of Social Psychology, 144(4), 407-420. https://doi.org/10.3200/SOCP.144.4.407-420

DePaola, S. J., Neimeyer, R. A., \& Ross, S. K. (1994). Death concern and attitudes toward the elderly in nursing home personnel as a function of training. OMEGA - Journal of Death and Dying, 29(3), 231-248. https://doi.org/10.2190/ TOLY-W07Y-VVX0-NMAP

Dickinson, G. E., Lancaster, C. J., Winfield, I. C., Reece, E. F., \& Colthorpe, C. A. (1997). Detached concern and death anxiety of first-year medical students: Before and after the gross anatomy course. Clinical Anatomy, 10(3), 201-207. https://doi.org/10.1002/(SICI)10982353

Du, H., Jonas, E., Klackl, J., Agroskin, D., Hui, E. K. P., \& Ma, L. (2013). Cultural influences on terror management: Independent and interdependent self-esteem as anxiety buffers. Journal of Experimental Social Psychology, 49(6), 1002-1011. https://doi.org/10.1016/j.jesp.2013.06.007

Echebarria Echabe, A., \& Perez, S. (2016). The impact of different procedures to arouse mortality awareness on various worldview dimensions. European Journal of Social Psychology, 46(3), 392-399. https://doi.org/10.1002/ejsp.2144

Elklit, A., Shevlin, M., Solomon, Z., \& Dekel, R. (2007). Factor structure and concurrent validity of the World Assumptions Scale. Journal of Traumatic Stress, 20(3), 291-301. https://doi.org/10.1002/jts.20203

Finkelstein, P., \& Mathers, L. H. (1990). Post-traumatic stress among medical students in the anatomy dissection laboratory. Clinical Anatomy, 3(3), 219-226. https://doi. org/10.1002/ca.980030308

Firth-Cozens, J., Midgley, S. J., \& Burges, C. (1999). Questionnaire survey of post-traumatic stress disorder in doctors involved in the Omagh bombing. BMJ (Clinical Research ed.), 319(7225), 1609. https://doi.org/10.1136/ bmj.319.7225.1609

Furer, P., \& Walker, J. R. (2008). Death anxiety: A cognitive-behavioral approach. Journal of Cognitive
Psychotherapy, 22(2), 167-182. https://doi.org/10.1891/ 0889-8391.22.2.167

Geronazzo-Alman, L., Eisenberg, R., Shen, S., Duarte, C. S., Musa, G. J., Wicks, J., Fan, B., Doan, T., Guffanti, G., Bresnahan, M., \& Hoven, C. W. (2017). Cumulative exposure to work-related traumatic events and current post-traumatic stress disorder in New York City's first responders. Comprehensive Psychiatry, 74, 134-143. https://doi.org/10.1016/j.comppsych.2016.12.003

Ghazanfar, H., Rashid, S., Hussain, A., Ghazanfar, M., Ghazanfar, A., \& Javaid, A. (2018). Cadaveric dissection a thing of the past? The insight of consultants, fellows, and residents. Cureus, 10(4), e2418. https://doi.org/10.7759/ cureus. 2418

Greenberg, J. (2008). Understanding the vital human quest for self-esteem. Perspectives on Psychological Science: A Journal of the Association for Psychological Science, 3(1), 48-55. https://doi.org/10.1111/j.1745-6916.2008.00061.x

Greenberg, J., \& Arndt, J. (2012). Terror management theory. In P. A. M. Van Lange, A. W. Kruglanski, \& E. T. Higgins (Eds.), The handbook of theories of social psychology (pp. 398-415). SAGE.

Greenberg, J., Pyszczynski, T., \& Solomon, S. (1986). The causes and consequences of a need for self-esteem: A Terror Management Theory. In R. F. Baumeister (Ed.), Public self and private self. Springer-Verlag.

Greenberg, J., Solomon, S., Pyszczynski, T., Rosenblatt, A., Burling, J., Lyon, D., Simon, L., \& Pinel, E. (1992). Why do people need self-esteem? Converging evidence that self-esteem serves an anxiety-buffering function. Journal of Personality and Social Psychology, 63(6), 913-922. https://doi.org/10.1037/0022-3514.63.6.913

Grills-Taquechel, A. E., Littleton, H. L., \& Axsom, D. (2011). Social support, world assumptions, and exposure as predictors of anxiety and quality of life following a mass trauma. Journal of Anxiety Disorders, 25(4), 498-506. https://doi.org/10.1016/j.janxdis.2010.12.003

Habicht, J. L., Kiessling, C., \& Winkelmann, A. (2018). Bodies for anatomy education in medical schools: An overview of the sources of cadavers worldwide. Academic Medicine: Journal of the Association of American Medical Colleges, 93(9), 1293-1300. https://doi.org/10.1097/ACM. 0000000000002227

Harmon-Jones, E., Simon, L., Greenberg, J., Pyszczynski, T., Solomon, S., \& McGregor, H. (1997). Terror Management Theory and self-esteem: Evidence that increased self-esteem reduced mortality salience effects. Journal of Personality and Social Psychology, 72(1), 24-36. https://doi.org/10.1037/0022-3514.72.1.24

Hintze, J., Templer, D. I., Cappelletty, G. G., \& Frederick, W. (1993). Death depression and death anxiety in HIVinfected males. Death Studies, 17(4), 333-341. https://doi. org/10.1080/07481189308252629

Hughes, B. M., \& Black, A. (2006). Body esteem as a moderator of cardiovascular stress responses in anatomy students viewing cadaver dissections. Journal of Psychosomatic Research, 61(4), 501-506. https://doi.org/ 10.1016/jpsychores.2006.05.004

Janoff-Bulman, R. (1989). Assumptive worlds and the stress of traumatic events: Applications of the schema construct. Social Cognition, 7(2), 113-136. https://doi.org/10. 1521/soco.1989.7.2.113 
Janoff-Bulman, R. (1992). Shattered assumptions: Towards a new psychology of trauma. The Free Press.

Janoff-Bulman, R. (1998). From terror to appreciation: Confronting chance after extreme misfortune. Psychological Inquiry, 9(2), 99-101. https://doi.org/10. 1207/s15327965pli0902_3

Kastenbaum, R. (2000). The psychology of death. Springer.

Klackl, J., \& Jonas, E. (2019). Effects of mortality salience on physiological arousal. Frontiers in Psychology, 10, 1893. https://doi.org/10.3389/fpsyg.2019.01893

Lehto, R. H., \& Stein, K. F. (2009). Death anxiety: An analysis of an evolving concept. Research and Theory for Nursing Practice, 23(1), 23-41. https://doi.org/10.1891/ 1541-6577.23.1.23

Luce, A., Firth-Cozens, J., Midgley, S., \& Burges, C. (2002). After the Omagh bomb: Posttraumatic stress disorder in health service staff. Journal of Traumatic Stress, 15(1), 27-30. https://doi.org/10.1023/A:1014327110402

Madill, A., \& Latchford, G. (2005). Identity change and the human dissection experience over the first year of medical training. Social Science \& Medicine (1982)), 60(7), 1637-1647. https://doi.org/10.1016/j.socscimed.2004.08.035

Martz, E. (2004). Death anxiety as a predictor of posttraumatic stress levels among individuals with spinal cord injuries. Death Studies, 28(1), 1-17. https://doi.org/10. 1080/07481180490249201

McLachlan, J. C., \& Patten, D. (2006). Anatomy teaching: Ghosts of the past, present and future. Medical Education, 40(3), 243-253. https://doi.org/10.1111/j.13652929.2006.02401.x

Melo, C. G., \& Oliver, D. (2011). Can addressing death anxiety reduce health care workers' burnout and improve patient care? Journal of Palliative Care, 27(4), 287-295. https://doi.org/10.1177/082585971102700405

Mulu, A., \& Tegabu, D. (2012). Medical students' attitudinal changes towards cadaver dissection: A longitudinal study. Ethiopian Journal of Health Sciences, 22(1), 51-58.

Neimeyer, R. A. (2009). Constructions of death and loss: A personal and professional evolution. In R. Butler (Ed.), Reflections in personal construct theory (pp. 293-318). Wiley.

Neimeyer, R. A., Wittkowski, J., \& Moser, R. P. (2004). Psychological research on death attitudes: An overview and evaluation. Death Studies, 28(4), 309-340. https://doi. org/10.1080/07481180490432324

Peters, L., Cant, R., Payne, S., O’Connor, M., McDermott, F., Hood, K., Morphet, J., \& Shimoinaba, K. (2013). How death anxiety impacts nurses' caring for patients at the end of life: A review of literature. The Open Nursing Journal, 7, 14-21. https://doi.org/10.2174/ 1874434601307010014

Preacher, K. J., \& Kelley, K. (2011). Effect size measures for mediation models: Quantitative strategies for communicating indirect effects. Psychological Methods, 16(2), 93-115. https://doi.org/10.1037/a0022658

Pyszczynski, T., Greenberg, J., \& Solomon, S. (1999). A dual-process model of defense against conscious and unconscious death-related thoughts: An extension of Terror Management Theory. Psychological Review, 106(4), 835-845. https://doi.org/10.1037/0033-295X.106.4.835

Pyszczynski, T., Greenberg, J., Solomon, S., Arndt, J., \& Schimel, J. (2004). Why do people need self-esteem? A theoretical and empirical review. Psychological Bulletin, 130(3), 435-468. https://doi.org/10.1037/0033-2909.130.3.435

Pyszczynski, T., \& Kesebir, P. (2011). Anxiety buffer disruption theory: A terror management account of posttraumatic stress disorder. Anxiety, Stress, and Coping, 24(1), 3-26. https://doi.org/10.1080/10615806.2010.517524

Rosenblatt, A., Greenberg, J., Solomon, S., Pyszczynski, T., \& Lyon, D. (1989). Evidence for Terror Management Theory: I. The effects of mortality salience on reactions to those who violate or uphold cultural values. Journal of Personality and Social Psychology, 57(4), 681-690. https:// doi.org/10.1037/0022-3514.57.4.681

Routledge, C. (2012). Failure causes fear: The effect of selfesteem threat on death-anxiety. The Journal of Social Psychology, 152(6), 665-669. https://doi.org/10.1080/ 00224545.2012 .691915

Routledge, C., Ostafin, B., Juhl, J., Sedikides, C., Cathey, C., \& Liao, J. (2010). Adjusting to death: The effects of mortality salience and self-esteem on psychological wellbeing, growth motivation, and maladaptive behavior. Journal of Personality and Social Psychology, 99(6), 897-916. https://doi.org/10.1037/a0021431

Saw, A. (2018). A new approach to body donation for medical education: The Silent Mentor Programme. Malaysian Orthopaedic Journal, 12(2), 68-72. https://doi.org/10. 5704/MOJ.1807.015

Snelling, J., Sahai, A., \& Ellis, H. (2003). Attitudes of medical and dental students to dissection. Clinical Anatomy, 16(2), 165-172. https://doi.org/10.1002/ca.10113

Stephens, G. C., Rees, C. E., \& Lazarus, M. D. (2019). How does donor dissection influence medical Students' Perceptions of Ethics? A Cross-Sectional and Longitudinal Qualitative Study. Anatomical Sciences Education, 12(4), 332-348. https://doi.org/10.1002/ase.1877

Tomer, A., \& Eliason, G. (1996). Toward a comprehensive model of death anxiety. Death Studies, 20(4), 343-365. https://doi.org/10.1080/07481189608252787

Ulla, S., Coca, C., del Rincón, C., Díaz, J. L., Arranz, P., Remor, E. A., \& Bayés, R. (2003). Coping with death: Perceptions of health care professionals working in a pediatric intensive care unit and in a geriatric service. Illness, Crisis, \& Loss, 11(4), 318-336. https://doi.org/10. 1177/1054137303256534

van Tuijl, L. A., Glashouwer, K. A., Bockting, C. L. H., Tendeiro, J. N., Penninx, B. W. J. H., \& de Jong, P. J. (2016). Implicit and explicit self-esteem in current, remitted, recovered, and comorbid depression and anxiety disorders: The NESDA Study. PLoS One, 11(11), e0166116. https://doi.org/10.1371/journal.pone. 0166116 